\title{
Biochemical Studies on the Protective Effects of Picrorhiza kurroa in Experimentally Induced Hepatitis in Rats
}

\author{
Rangasamy Anandan, ${ }^{1, *}$ Ravikumar DeEPa ReKha, ${ }^{1}$ Thiruvengadam \\ DeVAKI, ${ }^{1}$ and Mani SANTHOSH KUMAR ${ }^{2}$ \\ ${ }^{1}$ Department of Biochemistry and Molecular Biology, University of Madras, \\ Guindy Campus, Chennai 600 025, India \\ ${ }^{2}$ Department of Medical Biochemistry, Dr. A.L.M. Post Graduate \\ Institute of Basic Medical Sciences, University of Madras, \\ Taramani Campus, Chennai 600 113, India
}

(Received January 18, 2000)

\begin{abstract}
Summary The effect of pre-treatment with an alcoholic extract of Picrorhiza kurroa, a herbal drug, on D-galactosamine-induced hepatitis in rats was investigated with respect to the activities of serum marker enzymes, glycolytic enzymes, gluconeogenic enzymes, glucose-6-phosphate dehydrogenase, and membrane-bound ATPases and the levels of lipid peroxides and hepatic thiols. Prior oral treatment with P. kurroa extract significantly prevented the D-galactosamine-induced increases in the activities of serum marker enzymes, glycolytic enzymes, glycogen phosphorylase, and glucose-6-phosphate dehydrogenase and the decreases in the activities of key gluconeogenic enzymes and membrane-bound ATPases in the liver. The extract also exerted an antioxidant effect against D-galactosamine-induced hepatitis by blocking the induction of lipid peroxidation and by preventing the depletion of hepatic thiols. The present findings confirm that $P$. kurroa is hepatoprotective in experimentally induced hepatitis in rats.
\end{abstract}

Key Words: Picrorhiza kurroa, D-galactosamine hepatitis, glycolytic enzymes, gluconeogenic enzymes, membrane-bound ATPases

A single intraperitoneal injection of D-galactosamine (GalN), an amino sugar, produces acute reversible hepatocellular injury in rats that morphologically resembles both drug-induced hepatitis and viral hepatitis in human beings $[1,2]$. The primary disturbance of the injury has been reported to involve a depletion of uridine nucleotides [3] and subsequent suppression of RNA synthesis $[4,5]$.

* To whom correspondence should be addressed. *Present Address: Biochemistry and Nutrition Division, Central Institute of Fisheries Technology, Cochin 682 029, India.

E-mail : kranandan@ cift.ker.nic.in 
GalN hepatitis is characterized by a progressive rise in liver enzymes, total bilirubin, ammonia, and lactate and is associated with coagulopathy, hypoglycemia, coma, and brain death [6]. The effects of GalN-induced hepatitis on energy metabolism are due to a reduction in gluconeogenesis and involve a shift from aerobic metabolism to anaerobic glycolysis [7]. Also, Shanne et al. [8] have reported that the appearance of GalN injury is dependent on intracellular $\mathrm{Ca}^{2+}$ concentrations. Peroxidation of endogenous lipid is also a major factor in the cytotoxic action of GalN [9].

Medicinal plants have been used to cure human illness since time immemorial, and certain of these drugs are believed to promote positive health and to maintain organic resistance against infection by re-establishing body equilibrium and by conditioning the body tissues [10]. Picrorhiza kurroa Royle ex Benth (Scrophulariaceae) is a small perennial herb distributed in the alpine Himalayas tract and in some tropical parts of India. It is commonly called "kutuki" and has high priority and applicability as an indigenous medicine to cure viral hepatitis and various liver disorders [10-12]. The extract also possesses diaphoretic, antiperiodic, stimulating, and expectorant properties, and it is used in traditional medicine to cure heart ailments, lung diseases, abdominal pain, stomach disorders, anemia, and jaundice and for promoting bile secretion $[10,12]$. The iridoid glycosides present in the roots of $P$. kurroa are well known for their free radicalscavenging activities[13].

We have already reported the hepatoprotective effect of $P$. kurroa on mitochondrial function [14-16], the tissue defense system [17], protein metabolism [18], and erythrocyte membrane function [19] in GalN-induced hepatitis in rats. We have also reported the antiulcerogenic effects of an ethanolic extract of $P$. kurroa on $\mathrm{HCl}$ /ethanol-induced ulcer in rats [20]. However, its protective effects on key enzymes of glucose metabolism, lipid peroxidation, and membrane-bound ATPases in GalN-induced hepatitis in rats have not yet been explored. Therefore, the present study was undertaken to examine the preventive effects of an ethanolic extract of $P$. kurroa rhizomes and roots $(P K)$ on glucose metabolism, lipid peroxidation, and hepatic thiol status in GalN-induced liver intoxication in rats.

\section{MATERIALS AND METHODS}

GalN was obtained from the Sigma Chemical Company, St. Louis, MO, USA. All other chemicals used were of analytical grade. $P K$ prepared (yield: $8.8 \%$ ) from dried rhizomes and roots of $P$. kurroa, authenticated by Captain Sreenivasamurthi Drug Research Institute for Ayurveda, Arumbakkam, Chennai, India, was obtained from TTK Pharmaceuticals, Chennai, India [18].

Male Wistar rats weighing about $120-150 \mathrm{~g}$ were obtained from FIPPAT, Padappai, Chennai, India, and housed in polyurethane cages under hygienic conditions at normal room temperature $\left(25-30^{\circ} \mathrm{C}\right)$. They were allowed commercial pelleted feed (M/s. Hindustan Lever Foods, Bangalore, India) and water ad libitum. 
The experimental animals were divided into four groups of 6 rats each. Group I served as the control. Group II animals were intraperitoneally (i.p.) injected twice with GalN (500 mg/kg body wt, dissolved in physiological saline), once on one day, and once on the next day for the induction of hepatitis [21]. Group III animals were orally pre-treated with $P K(50 \mathrm{mg} / \mathrm{kg}$ body wt/day, dissolved in distilled water and given daily for 10 days) and then i.p. injected with GalN (500 $\mathrm{mg} / \mathrm{kg}$ body wt/day) as in Group II. Group IV animals were orally treated with $P K$ alone at the above dosage for 10 days.

At the end of $24 \mathrm{~h}$ after the last injection of GalN, the animals were killed by decapitation. Blood was collected without any anticoagulant, and the separated serum was used for the assay of marker enzymes such as aspartate aminotransferase (AST) [22], alanine aminotransferase (ALT) [22], acid phosphatase (ACP) [23], alkaline phosphatase (ALP) [23], and lactate dehydrogenase (LDH) [24]. The liver was dissected out immediately, washed with chilled isotonic saline, and homogenized in ice-cold $0.1 \mathrm{M}$ Tris- $\mathrm{HCl}$ buffer, $\mathrm{pH} 7.2$, in a Potter-Elvehjem homogenizer for the estimation of hexokinase [25], aldolase [26], LDH [24], glucose-6-phosphatase [27], fructose-1,6-diphosphatase [28], glycogen phosphorylase [29], glucose-6-phosphate dehydrogenase [30], lipid peroxides [31], $\mathrm{Na}^{+}$ $\mathrm{K}^{+}$-ATPase [32], $\mathrm{Mg}^{2+}$-ATPase [33], $\mathrm{Ca}^{2+}$-ATPase [34], and thiols (total, protein-bound, and non-protein) [35]. The blood sugar was estimated by the method of Sasaki et al. [36]; proteins, by the method of Lowry et al. [37], and hepatic glycogen, by the method of Morales et al. [38].

Results were expressed as the mean $\pm \mathrm{SD}$, and Student's $t$-test was used to assess statistical significance.

\section{RESULTS}

The elevation of activities of serum ALT, AST, ACP, ALP, and LDH caused by GalN intoxication was significantly $(p<0.001)$ prevented in $P$. kurroa extract pre-treated rats (Table 1). Increased activities of glycolytic enzymes, glycogen phosphorylase and glucose-6-phosphate dehydrogenase and decreased activities of key gluconeogenic enzymes and membrane-bound ATPases and lowered levels of blood glucose and hepatic glycogen content observed in GalN toxic rats were also significantly avoided by the $P K$ pre-treatment in Group III rats (Tables 2 and 3).

Intraperitoneal administration of GalN also caused a significant increase in lipid peroxidation in liver with a significant decrease in hepatic thiol content as compared with the level in normal control rats (Table 3). The oral pre-treatment with $P K$ significantly prevented all these adverse effects and maintained the levels of the evaluated parameters nearly at normal values. The normal rats receiving $P K$ alone did not show any significant changes when compared with the control animals, indicating that $P K$ does not have any adverse effect. 
Table 1. Activities of serum alanine aminotransferase (ALT), aspartate aminotransferase (AST), acid phosphatase (ACP), alkaline phosphatase (ALP), and lactate dehyrogenase (LDH) in normal and experimental groups of rats (mean \pm SD for 6 animals in each groups).

\begin{tabular}{lrccr}
\hline Group & Group I & Group II & Group III & Group IV \\
\hline ALT & $110.8 \pm 9.8$ & $374.3 \pm 35.9^{* * *}$ & $133.4 \pm 11.6^{* * *}$ & $112.9 \pm 10.3$ \\
AST & $85.7 \pm 6.2$ & $395.8 \pm 36.4^{* * *}$ & $118.6 \pm 9.7^{* * *}$ & $89.3 \pm 6.6$ \\
ACP & $12.6 \pm 1.0$ & $39.7 \pm 2.1^{* * *}$ & $19.2 \pm 1.2^{* * *}$ & $11.8 \pm 0.8$ \\
ALP & $108.7 \pm 8.9$ & $263.8 \pm 14^{* * *}$ & $126.2 \pm 10.5^{* * *}$ & $109.2 \pm 11.2$ \\
LDH & $215.6 \pm 19.8$ & $398.5 \pm 26.4^{* * *}$ & $228.6 \pm 19.6^{* * *}$ & $212.3 \pm 17.4$ \\
\hline
\end{tabular}

Group I, normal controls; group II, D-galactosamine-intoxicated rats; group III, $P K$ pretreated and D-galactosamine-intoxicated rats; group IV, normal rats treated with $P K$ alone. Values are expressed as $\mu \mathrm{mol}$ of pyruvate liberated/h/liter for ALT, AST, and LDH and as $\mu \mathrm{mol}$ of phenol liberated $/ \mathrm{h} /$ liter for ACP and ALP.

As compared with respective controls, i.e., group II vs. group I, group III vs. group II: $* * * p<0.001$.

Table 2. Levels of blood glucose and hepatic glycogen and the activities of liver hexokinase, aldolase, lactate dehydrogenase (LDH), glucose-6-phosphatase, fructose-1,6-diphosphatase, glycogen phosphorylase, and glucose-6-phosphate dehydrogenase in normal and experimental groups of rats (mean \pm SD for 6 animals in each group).

\begin{tabular}{lcccc}
\hline Group & Group I & Group II & Group III & Group IV \\
\hline Blood glucose & $88.6 \pm 6.33$ & $64.6 \pm 4.98^{* * *}$ & $77.1 \pm 5.74^{* *}$ & $86.9 \pm 6.36$ \\
Glycogen & $34.7 \pm 3.08$ & $16.2 \pm 2.86^{* * *}$ & $30.3 \pm 3.96^{* * *}$ & $35.6 \pm 3.42$ \\
Hexokinase & $14.9 \pm 2.18$ & $24.7 \pm 3.31^{* *}$ & $16.3 \pm 2.24^{* *}$ & $15.6 \pm 1.15$ \\
Aldolase & $15.6 \pm 2.91$ & $23.4 \pm 3.24^{* *}$ & $18.5 \pm 2.36^{* *}$ & $15.3 \pm 2.67$ \\
LDH & $12.4 \pm 1.33$ & $24.7 \pm 3.78^{* * *}$ & $15.4 \pm 2.22^{* *}$ & $12.5 \pm 2.18$ \\
Glucose-6-phosphatase & $2.19 \pm 0.26$ & $1.23 \pm 0.18^{* * *}$ & $1.98 \pm 0.20^{* *}$ & $2.21 \pm 0.24$ \\
Fructose-1,6-diphosphatase & $17.8 \pm 1.86$ & $8.46 \pm 0.49^{* * *}$ & $15.96 \pm 1.42^{* * *}$ & $11.5 \pm 1.81$ \\
Glycogen phosphorylase & $36.4 \pm 4.34$ & $20.1 \pm 3.07^{* *}$ & $32.6 \pm 3.18^{* * *}$ & $37.2 \pm 4.01$ \\
Glucose-6-phosphate dehydrogenase & $3.52 \pm 0.14$ & $6.45 \pm 0.38^{* * *}$ & $4.13 \pm 0.25^{* *}$ & $3.46 \pm 0.14$ \\
\hline
\end{tabular}

Group designations are the same as in Table 1.

Values are expressed as follows: Blood glucose, $\mathrm{mg} / \mathrm{dl}$; glycogen, $\mathrm{mg} / \mathrm{g}$ liver; hexokinase, nmol of glucose-6-phosphate formed $/ \mathrm{min} / \mathrm{mg}$ protein; aldolase, nmol of glyceraldehyde-3phosphate $/ \mathrm{h} / \mathrm{mg}$ protein; lactate dehydrogenase, $\mu \mathrm{mol}$ of pyruvate formed $/ \mathrm{min} / \mathrm{mg}$ protein; glucose-6-phosphatase, $\mu \mathrm{mol}$ of $\mathrm{Pi}$ liberated $/ \mathrm{min} / \mathrm{mg}$ protein; fructose-1,6-diphosphatase and glycogen phosphorylase, nmol of $\mathrm{Pi}$ liberated $/ \mathrm{min} / \mathrm{mg}$ protein; glucose-6-phosphate dehydrogenase, units/mg protein.

As compared with respective controls, i.e., group II $v s$. group I, group III vs. group II; $* * * p<0.001, * * p<0.01$.

\section{DISCUSSION}

Increased activities of AST, ALT, ACP, ALP, and LDH in serum are well known diagnostic indicators of GalN-induced hepatitis $[3,39,40]$. In cases of liver damage with hepatocellular lesions and parenchymal cell necrosis, these marker enzymes are released from damaged tissues into the bloodstream [41]. Prior oral administration of $P K$ resulted in significant reduction in the activities of these marker enzymes towards near-normalcy, as compared with the levels in the 
Table 3. Levels of lipid peroxides and thiols and the activities of membrane-bound ATPases in livers from normal and experimental groups of rats (mean \pm SD for 6 animals in each group).

\begin{tabular}{lcccr}
\hline Group & Group I & \multicolumn{1}{l}{ Group II } & \multicolumn{1}{l}{ Group III } & \multicolumn{1}{c}{ Group IV } \\
\hline I. Lipid peroxidation & & & & \\
Basal & $1.43 \pm 0.18$ & $2.21 \pm 0.25^{* * *}$ & $1.64 \pm 0.16^{* * *}$ & $1.48 \pm 0.16$ \\
$t$-Butyl hydroperoxide & $10.41 \pm 1.16$ & $15.64 \pm 1.68^{* * *}$ & $12.18 \pm 1.22^{* *}$ & $10.37 \pm 1.20$ \\
FeSO & $14.94 \pm 1.28$ & $24.16 \pm 1.45^{* * *}$ & $16.90 \pm 1.31^{* * *}$ & $15.08 \pm 1.24$ \\
$\quad$ Ascorbate & $6.89 \pm 1.04$ & $12.87 \pm 1.12^{* * *}$ & $8.27 \pm 1.10^{* *}$ & $6.82 \pm 1.06$ \\
II. Membrane-bound ATPases & & & \\
$\mathrm{Ca}^{2+}$-ATPase & $0.82 \pm 0.07$ & $0.61 \pm 0.05^{* * *}$ & $0.74 \pm 0.07^{* * *}$ & $0.79 \pm 0.08$ \\
$\mathrm{Na}^{+}, \mathrm{K}^{+}$-ATPase & $1.25 \pm 0.08$ & $0.98 \pm 0.05^{* * *}$ & $1.09 \pm 0.06^{* *}$ & $1.23 \pm 0.07$ \\
$\mathrm{Mg}^{2+}$-ATPase & $1.36 \pm 0.12$ & $1.15 \pm 0.18^{*}$ & $1.31 \pm 0.16^{*}$ & $1.34 \pm 0.14$ \\
III. Thiols & & & & \\
Total & $410.12 \pm 29.15$ & $248.65 \pm 24.12^{* * *}$ & $368.44 \pm 26.63^{* * *}$ & $406.98 \pm 30.08$ \\
$\quad$ Protein-bound & $386.83 \pm 30.12$ & $228.72 \pm 24.43^{* * *}$ & $342.16 \pm 27.33^{* * *}$ & $382.27 \pm 29.82$ \\
$\quad$ Non-protein & $3.23 \pm 0.63$ & $5.82 \pm 0.73^{* * *}$ & $3.92 \pm 0.68^{* *}$ & $3.18 \pm 0.64$ \\
\hline
\end{tabular}

Group designations are the same as in Table 1.

Values are expressed as follows: Lipid peroxidation, nmol of thiobarbituric acid-reactive substance $/ \mathrm{mg}$ protein; membrane-bound ATPases, $\mu \mathrm{mol}$ of Pi liberated $/ \mathrm{min} / \mathrm{mg}$ protein; thiols, nmol/g wet liver.

As compared with respective controls, i.e., group II $v s$. group I, group III $v s$. group II: $* * * p<$ $0.001 ;{ }^{*} p<0.01 ;{ }^{*} p<0.05$.

Group II GalN-intoxicated rats, indicating the cytoprotective effect of this extract.

The observed GalN-induced hypoglycemia may be due to an activated pancreatic $\beta$-cell function and to the decreased activities of the key gluconeogenic enzymes and/or increased activities of glucose-utilizing enzymes [39, 42]. Injection of GalN induces depletion of glycogen in the liver rather than new synthesis of glycogen [43]. Increased activities of glycolytic enzymes (hexokinase, aldolase, and lactate dehydrogenase) in Group II GalN-toxic rats, which is in line with previous reports $[7,39,43]$ indicate that GalN-induced depletion of ATP synthesis in the impaired mitochondria may induce an activation of glycolysis, disappearances of glycogen granules and accumulation of hepatocellular fat.

Activities of the principal gluconeogenic enzymes (glucose-6-phosphatase and fructose-1,6-diphosphatase) have been previously reported to be decreased in GalN hepatitis along with an increase in the ratio of key gluconeogenic to glycolytic enzymes, thus leading to GalN-induced hypoglycemia $[6,7,44]$. The significantly increased glycogen phosphorylase activity observed in Group II GalN-intoxicated rats indicates increased glycogenolysis. The damage to liver cell integrity caused by fatty degeneration after GalN administration might be the cause of both decreased glycogenesis and increased glycogenolysis. The rats pre-treated with $P K$ showed nearly normal levels of blood glucose, hepatic glycogen content, and the activities of glycolytic enzymes, gluconeogenic enzymes and glycogen phosphorylase as compared with Group II GalN-intoxicated rats. It probably did so by inhibiting the glycogen depletion or by increasing gluconeogenesis [14].

Vol. 29, 2000 
The hexose monophosphate shunt pathway is one of the NADPH-generating systems. A significant increase in the activity of glucose-6-phosphate dehydrogenase in GalN hepatitis has already been reported [7]. The prior oral treatment with $P K$ in our study prevented the GalN-induced increase in glucose-6phosphate dehydrogenase activity, thus reducing the availability of NADPH for excess fatty acid synthesis and establishing its hypolipidemic effect [11].

A significant rise in the level of lipid peroxides following GalN intoxication in our study suggests that glucose auto-oxidation related to GalN-induced hypoglycemia $[42,45]$ might be responsible for the increased generation of free radicals in GalN hepatitis. The rats pre-treated with $P K$ showed a significant decrease in lipid peroxidation as compared with the Group II GalN-intoxicated rats. We suspect that this antioxidant effect was due to the presence two electrophilic substances called "picroside I and kutkoside" present in the roots of P. kurroa [11]. The unpaired electron present in the hydroxyl free radicals generated by GalN [46] might have been trapped by picroside I and kutkoside.

Activities of $\mathrm{Na}^{+}, \mathrm{K}^{+}$-ATPase, $\mathrm{Mg}^{2+}$-ATPase and $\mathrm{Ca}^{2+}$-ATPase in the liver were significantly lower in Group II GalN toxic rats, which is in line with previous reports [9]. The intracellular concentration of calcium regulates the activity of the $\mathrm{Mg}^{2+}$ and $\mathrm{Na}^{+}, \mathrm{K}^{+}$-ATPases. Bironaite and Ollinger [47] have reported that lipid peroxidation can influence the function of $\mathrm{Ca}^{2+}$ and $\mathrm{Mg}^{2+}$-ATPases and the activity of membrane $\mathrm{Ca}^{2+}$-translocase. Levels of membrane protective thiols, both protein bound and non-protein bound showed a notable decrease in the rats with GalN hepatitis, which also agrees with previous reports [48, 49]. The marked loss in the activities of membrane-bound ATPases registered in GalN hepatitis may also be due to the loss of protein-SH, because of increased lipid peroxidative damage of cell membranes.

Prior oral treatment with $P K$ in our study largely prevented the abovementioned GalN-induced alterations in the $\mathrm{Na}^{+}, \mathrm{K}^{+}$-ATPase, $\mathrm{Mg}^{2+}$-ATPase, and $\mathrm{Ca}^{2+}$-ATPase activities and in the protein and non-protein thiol levels found in the Group II GalN-induced hepatotoxic rats. It probably did so by its antioxidant nature [13] against lipid peroxidation induced by GalN [9]. This present study confirms the hepatoprotective effect of $P$. kurroa against GalN-induced hepatitis in rats.

\section{REFERENCES}

1. Gu, C.H., Cao, R., and Wang, G.X. (1991): Protective effect of prostaglandin E on hepatocytes and its value of early treatment of severe viral hepatitis. Chung Hua Nei Ko Tsa Chih, 30, 17-20.

2. Jonker, A.M., Dijkhuis, F.W., Boes, A., Hardonk, M.J., and Grond, J. (1991): Immunohistochemical study of extracellular matrix in acute galactosamine hepatitis in rats. Hepatology, 15, 423-431.

3. Manabe, A., Cheng, C.C., Egashira, Y., Ohta, T., and Sanada, H. (1996): Dietary wheat gluten alleviates the elevation of serum transaminase activities in D-galactosamine-injected rats. J. Nutr. Sci. Vitaminol. (Tokyo), 42, 121-132. 
4. Giesen, E.M., Beck, G., Holstege, A., and Keppler, D.O.R. (1981): Inhibition of tyrosine aminotransferase induction by UTP deficiency and its reversal by 5 -fluorouridine in cultured hepatoma cells. Biochim. Biophys. Acta, 651, 34-40.

5. Endo, Y., Kikuchi, T., and Nakamura, M. (1992): Ornithine and histidine decarboxylase activities in mice sensitized to endotoxin, interleukin-1 or tumor necrosis factor by Dgalactosamine. Br. J. Pharmacol., 107, 888-894.

6. Rao, S., McGuire, B., Bloomer, J.R., Hu, W.S., and Cerra, F.B. (1995): Gel entrapment bioartificial liver therapy in galactosamine hepatitis. J. Surg. Res., 59, 179-184.

7. Yamamoto, C., Mori, S., Murakami, K., and Yoshino, M. (1995): Effect of D-galactosamineinduced hepatitis on the aerobic and anaerobic metabolism of the rat exposed to high altitude hypoxia. Comp. Biochem. Physiol. Pharmacol. Toxicol. Endocrinol., 110, 83-87.

8. Shanne, F.A.X., Pfau, R.G., and Farber, J.L. (1980): Galactosamine-induced cell death in primary cultures of rat hepatocytes. Am. J. Pathol., 100, 25-38.

9. Sakaguchi, S., and Yokota, K. (1995): Role of $\mathrm{Ca}^{2+}$ on endotoxin-sensitivity by galactosamine challenge: lipid peroxide formation and hepatotoxicity in zymosan-primed mice. Pharmacol. Toxicol., 77, 81-86.

10. Atal, C.K., Sharma, M.L., Kaul, A., and Khajuria, A. (1985): Immunomodulating agents of plant origin. I: Preliminary screening. J. Ethanopharmacol., 18, 133-141.

11. Anand, N. (1990): Contributions of ayurvedic medicine to medicinal chemistry, in Comprehensive Medicinal Chemistry, Vol. I, ed. by Hansch, C., Sammes, P.G., Taylor, J.B., and Kennewell, P.D., Pergamon Press, Plc, Oxford, pp. 113-131.

12. Kapahi, B.K., Srivastava, T.N., and Sarin, Y.K. (1993): Description of Picrorhiza kurroa, a source of the ayurvedic drug "Kutuki." Int. J. Pharmacogn., 31, 217-222.

13. Ramesh, C., Kapoor, N.K., and Dhawan, B.N. (1992): Picroliv, Picroside I and Kutkoside from Picrorhiza kurroa are scavengers of superoxide anions. Biochem. Pharmacol., 44, 180183.

14. Anandan, R., and Devaki, T. (1998): Biochemical studies on the antihepatotoxic potential of Picrorhiza kurroa on mitochondrial damage in D-galactosamine-induced liver intoxication in rats. Med. Sci. Res., 26, 349-352.

15. Anandan, R., Rekha, R.D., and Devaki, T. (1999): Protective effect of Picrorhiza kurroa on mitochondrial glutathione antioxidant system in D-galactosamine-induced hepatitis in rats. Curr. Sci., 76, 1543-1545.

16. Anandan, R., Prabakaran, M., and Devaki, T. (1999): Biochemical studies on the hepatoprotective effect of Picrorhiza kurroa on changes in liver mitochondrial respiration and oxidative phosphorylation in D-galactosamine-induced hepatitis in rats. Fitoterapia, 70, 548-551.

17. Anandan, R., and Devaki, T. (1999): Hepatoprotective effect of Picrorhiza kurroa on tissue defense system in D-galactosamine-induced hepatitis in rats. Fitoterapia, 70, 54-57.

18. Anandan, R., Priya, M.S., Devi, K.P., and Devaki, T. (1999): Protective effect of Picrorhiza kurroa against D-galactosamine-induced hepatitis in rats. Med. Sci. Res., 27, 127-130.

19. Anandan, R., Devi, K.P., Devaki, T., and Govidaraju, P. (1998): Preventive effects of Picrorhiza kurroa on D-galactosamine-induced hepatitis in rats. J. Clin. Biochem. Nutr., 25, 87-95.

20. Anandan, R., Rekha, R.D., Saravanan, N., and Devaki; T. (1999): Protective effect of Picrorhiza kurroa against $\mathrm{HCl}$ /ethanol-induced ulceration in rats. Fitoterapia, 70, 498-501.

21. Deaciuc, I.V., Bagby, G.J., and Spitzer, J.J. (1993): Association of galactosamine-induced hepatitis in the rat with hyaluronaemia and decreased hyaluronan uptake by the isolated, perfused liver. Biochem. Pharmacol., 46, 671-675.

22. Mohur, A., and Cook, I.J.Y. (1957): Simple methods for measuring serum levels of glutamicoxaloacetic and glutamic-pyruvic transaminase in routine laboratories. J. Clin. Pathol., 10, 394-399.

23. King, J. (1965): The hydrolases-acid and alkaline phosphatases, in Practical Clinical Enzymology, ed. by Van, D., Nostrand Co., London, pp. 191-208.

24. King, J. (1965): Lactate dehydrogenase, in Practical Clinical Enzymology, ed. by Van, D.,

Vol. 29, 2000 
Nostrand Co., London, pp. 83-93.

25. Brankstrup, N., Kirk, J.E., and Bruni, C. (1957): The hexokinase and phosphoglucoisomerase activities of aortic and pulmonary artery tissues in individuals of various ages. $J$. Gerontol., 12, 166-171.

26. King, J. (1965): Aldolase, in Practical Clinical Enzymology, ed. by Van, D., Nostrand Co., London, pp. 289-310.

27. Koide, H., and Oda, T. (1959): Pathological occurrence of glucose-6-phosphatase in serum in liver diseases. Clin. Chim. Acta, 1, 549-553.

28. Gancedo, J.M., and Gancedo, C. (1971): Fructose-1,6-diphosphatase, phosphofructokinase, and glucose-6-phosphate dehydrogenase from fermenting and non-fermenting yeasts. Arch. Mikrobiol., 76, 131-138.

29. Cornblath, M., Randle, P.J., Parmeggiani, A., and Morgan, H.E. (1963): Regulation of glycolysis in muscle: Effects of glucagon and anoxia on lactate production, glycogen content, and phosphorylase activity in the perfused isolated rat heart: J. Biol. Chem., 238, 1592-1597.

30. Beutler, E. (1967): Glucose-6-phosphate dehydrogenase deficiency, diagnosis, clinical and genetic implications. Am. J. Clin. Pathol., 47, 303-311.

31. Ohkawa, H., Ohishi, N., and Yagi, K. (1979): Assay for lipid peroxides in animal tissue by thiobarbituric acid reaction. Anal. Biochem., 95, 351-358.

32. Bonting, S.L. (1970): Sodium-potassium activated adenosine triphosphatase and carbon transport, in Membrane and Iron Transport, Vol. I., ed. by Bittar, E.E., Wiley-Interscience, London, pp. 257-363.

33. Ohnishi, T., Suzuki, T., Suzuki, Y., and Ozawa, K. (1982): A comparative study of plasma membrane magnesium ion ATPase activities in normal regenerating and malignant cells. Biochim. Biophys. Acta, 684, 67-74.

34. Hjerten, S., and Pan, H. (1983): Purification and characterization of two forms of low affinity calcium ion-ATPase from erythrocyte membranes. Biochim. Biophys. Acta, 755, 457466.

35. Sedlak, J., and Lidsay, R.H. (1968): Estimation of total, protein-bound and non-protein sulphhydryl groups in tissues with Ellman's reagent. Anal. Biochem., 25, 192-205.

36. Sasaki, T., and Matsui, S. (1972): Effect of acetic acid concentration on the colour reaction in the O-toluidine-boric acid method for blood glucose determination. Rinsho Kagaku, 1, 346-353 (in Japanese).

37. Lowry, O.H., Rosebrough, N.J., Farr, A.L., and Randall, R.J. (1951): Protein determination using Folin-phenol reagent. J. Biol. Chem., 193, 265-275.

38. Morales, M.A., Jabbagy, A.J., and Terenizi, H.R. (1973): Mutations affecting accumulation of glycogen. Neurospora Newsl., 20, 24-30.

39. McMillan, J.M., and Jollow, D.J. (1995): Macrophage enhancement of galactosamine hepatotoxicity using a rat hepatocyte culture system. Res. Commun. Mol. Pathol. Pharmacol., 88, 327-338.

40. Hayashi, M., Yamazoe, H., Yamaguchi, Y., and Kunitomo, M. (1992): Effect of green tea extract on galactosamine-induced hepatic injury in rats. Nippon Yakurigaku Zasshi, 100, 391-399 (in Japanese).

41. Devaki, T., Venmadhi, S., and Govindaraju, P. (1992): Alterations in protein metabolism in ethanol-ingested rats treated with garlic oil. Med. Sci. Res., 20, 725-727.

42. Hyohun, P. (1996): Activated pancreatic $\beta$-cell function in acute liver injury in D-galactosamine-treated rats. Kyoto-furitsu Ika Daigaku Zasshi, 105, 491-501 (in Japanese).

43. Shinozuka, H., Farber, J.L., Konishi, Y., and Anukarahanta, T. (1973): D-Galactosamine and acute liver cell injury. Fed. Proc., 32, 1516-1526.

44. Dabeva, M.D., and Shafritz, D.A. (1993): Activation, proliferation and differentiation of progenitor cells into hepatocytees in the D-galactosamine model of liver regeneration. Am. J. Pathol., 143, 1606-1620.

45. Wolff, S.P., and Dean, R.T. (1987): Glucose autoxidation and protein modification. The potential role of autoxidative glycosylation in diabetes. Biochem. J., 245, 243-250. 
46. Hu, H.L., and Chen, R.D. (1992): Changes in free radicals, trace elements, and neurophysiological function in rats with liver damage induced by D-galactosamine. Biol. Trace Elem. Res., 34, 19-25.

47. Bironaite, D., and Ollinger, K. (1997): The hepatotoxicity of rhein involves impairment of mitochondrial functions. Chem. Biol. Interact., 103, 35-50.

48. Irita, K., Okabe, H., Koga, A., Kurosawa, K., Tagawa, K., and Yamakawa, M. (1994): Increased sinusoidal efflux of reduced and oxidised glutathione in rats with endotoxin/ D-galactosamine hepatitis. Circ. Shock, 42, 115-120.

49. Okabe, H., Irita, K., Kurosawa, K., Tagawa, K., Koga, A., Yamakawa, M. Yoshitake, J., and Takahashi, S. (1993): Increase in plasma concentration of reduced glutathione observed in rats with liver damage induced by lipopolysaccharide/D-galactosamine: Effect of uinastatin, a urinary trypsin inhibitor. Circ. Shock, 41, 268-272. 